\title{
Determination of Formation Time of Calcareous Cements in Marine Sandstone and Their Influence on Hydrocarbon Accumulation: A Case Study of the Carboniferous Donghe Sandstone in the Hadexun Oilfield, Tarim Basin
}

\author{
Jingwei Cui $\left(^{1}{ }^{1}\right.$ and Yongfu Liu ${ }^{2}$ \\ ${ }^{1}$ Research Institute of Petroleum Exploration Development, Beijing 100083, China \\ ${ }^{2}$ Exploration and Development Research Institute of PetroChina Tarim Oilfield Company, Korla, Xinjiang Province 841000, China \\ Correspondence should be addressed to Jingwei Cui; jingwei.cui@126.com
}

Received 16 September 2020; Revised 9 February 2021; Accepted 25 February 2021; Published 10 March 2021

Academic Editor: Basim Abu-Jdayil

Copyright (C) 2021 Jingwei Cui and Yongfu Liu. This is an open access article distributed under the Creative Commons Attribution License, which permits unrestricted use, distribution, and reproduction in any medium, provided the original work is properly cited.

\begin{abstract}
Based on core observations, the microheterogeneity, diagenetic features, diagenetic mineral compositions, and stable isotopes of cements in the calcareous interlayers in the Donghe sandstone were studied by polarizing microscopy, cathodoluminescence microscopy, X-ray diffractometry, isotope ratio mass spectrometry, and other techniques. By determining the proportions of cements of two phases by a statistical method and their clumped isotope values by an end-member method, the multiphase calcareous cementation was shown to be the major contributor to densification. Cluster isotopes revealed that the average formation temperatures of calcareous cements in phases II and III of cementation were $45-50^{\circ} \mathrm{C}$ and $80-90^{\circ} \mathrm{C}$, indicating that they were products of the $\mathrm{A}$ and $\mathrm{B}$ phases during early diagenesis, respectively. According to the homogenization temperatures of coeval salt-water inclusions associated with hydrocarbon inclusions, which range from $100^{\circ} \mathrm{C}$ to $130^{\circ} \mathrm{C}$, basin modeling revealed that the basin underwent mainly one stage of hydrocarbon charging during $8-5 \mathrm{Ma}$ in the Miocene period. The cements of the two phases in the oil-free calcareous interlayers in the Donghe sandstone, which are the main controlling factor of the oil-water distribution in the reservoir at present, formed much earlier than the oil filling in the oil-bearing sandstone.
\end{abstract}

\section{Introduction}

In the past 30 years, several large oil and gas fields (such as the Donghetang Oilfield, Tazhong 4 Oilfield, and Hadexun Oilfield) have been discovered successively in the Carboniferous Donghe sandstone, which has become an important high-yielding formation in the Tarim Basin $[1,2]$. The Hadexun Oilfield is the first marine sandstone oilfield with reserves of more than 700 million barrels of oil in place (MBOIP) discovered in the Tarim Basin. Its main production layers include the Carboniferous marine Donghe sandstone and thin sandstone layers in the middle mudstone sections, which are hydrodynamic reservoirs rather than gravity reservoirs [3]. Several previous studies have been carried out on the Donghe sandstone, including studies of its sedimentation and provenance, reservoir characteristics, oil and gas source, and accumulation process, and important understandings were achieved [4-11]. As the oil field entered the middlelate development stage of high water cut (more than $80 \%$ ), its production entered a declining stage. Therefore, the formation and spatial distribution of interlayers in the sandstone are of great significance to the design and adjustment of the development plan of the oil field [12].

Some important progress in the study of the interlayers in the Donghe sandstone has been made. There are three types of septums in the Donghe sandstone, namely, the calcareous septum, the argillaceous carbonate septum, and the argillaceous septum, which are sedimentary and diagenetic $[1,13-15]$. These septums have small thickness, ranging narrowly from $0.02 \mathrm{~m}$ to $0.6 \mathrm{~m}$, with an average of about 
$0.2 \mathrm{~m}$, and occur mainly in masses, spots, beddings, and quasilamellae or lamellae. The calcareous cementation in calcareous sandstone was formed by two to four phases, which separated the upper and lower fluids and controlled the change of sea level $[8,12,16,17]$. As the diagenetic evolution of a sandstone reservoir is a very complex physicochemical process controlled by numerous factors, including sedimentation, structural evolution, mineral composition, burial, heat flow properties, fluid migration, and sequence development, it is difficult to determine the formation temperature and timing of cements accurately $[18,19]$.

Clumped isotope analysis of carbonates, as an innovative paleothermometer, can directly provide formation temperature information of a mineral, with no assumptions about the isotopic values of paleofluids [20,21]. At present, its application has been expanded successfully to include analyses of reservoir diagenetic evolution, paleoclimate, paleoelevation reconstruction, structural evolution analysis, genetic analysis of natural gas, and paleothermal history reconstruction, and a series of new understandings has been achieved [22-27]. Because the original clumped isotopes within the lattice of a carbonate mineral are retained well during the process of acid digestion, mass-47 $\mathrm{CO}_{2}\left({ }^{13} \mathrm{C}^{18} \mathrm{O}^{16} \mathrm{O}(\Delta 47)\right)$ can be used as an approximation of isotopologue ${ }^{13} \mathrm{C}^{18} \mathrm{O}^{16} \mathrm{O}^{2-}$ in carbonate rocks, and the abundance of mass-47 $\mathrm{CO}_{2}$ can represent the abundance of ${ }^{13} \mathrm{C}-{ }^{18} \mathrm{O}$ bonds in a carbonate mineral [28]. The carbonate cluster isotope thermometer is based on the exchange reaction between ${ }^{13} \mathrm{C}$ and ${ }^{18} \mathrm{O}$, which depends mainly on temperature $[20,21]$. In recent years, many scholars have found that the carbonate clumped isotope information would change with increasing formation temperature under certain conditions; however, it can be predicted quantitatively by corresponding models $[29,30]$.

This study is aimed at examining the diagenetic characteristics, mineral composition, and cementation phase of calcareous interlayers in the Donghe sandstone in the Hadexun Oilfield based on microscopic analysis of casting thin sections, cathodoluminescence, and X-ray diffraction (XRD) to clarify the distribution of calcareous cements at the scale of the core and also to accurately define the formation time of calcareous cements in interlayers in the Donghe sandstone using clumped isotope analyses and basin modeling to evaluate their influence on hydrocarbon accumulation based on the burial history and thermal history of the basin.

\section{Geological Setting}

The Hadexun Oilfield is geographically located in the floodplain on the south bank of the Tarim River in Shaya County, Xinjiang Uygur Autonomous Region, and structurally located in the Hudexun structural belt in the northern Manjar sag. The Hadexun structural belt is connected with the Lunnan low bulge on the Tabei Uplift to the north, which is part of the nose structural belt as a southward extension of the Lunnan low bulge and is considered to be a typical uplift within a depression (Figure 1). It is a Carboniferous low-amplitude anticline, developed from the late Early Paleozoic-early Late Paleozoic uplift, extending from NE to
SW. The Carboniferous Donghe sandstone in the Hadexun Oilfield is in an unconformity relation with the overlying dark-red breccia and the underlying Silurian tight sandstone, and the reservoir is considered a large-scale stratigraphicstructural reservoir $[2,3]$.

The Donghe sandstone, widely distributed within the basin, is a set of sandstones or sandy conglomerates at the bottom of a transgressive system deposited on a landform that was low in the west and high in the east during the Late Devonian to Early Carboniferous. Generally, it consists of a set of thick sandstones characterized by distinct lithologicelectrical properties, good spatial continuity, relatively low macroheterogeneity, and high microheterogeneity, indicating that it is a typical set of barrier-free, wave-controlled, nearshore sandy deposits. The absence of an Upper Paleozoic structural layer resulted in the Devonian strata overlapping the Silurian strata directly. Influenced by tectonic inversion starting in the Late Himalayan period, the strata were higher and thicker in the south than in the north. The MesozoicCenozoic structural layer is thinner and higher in the south than in the north [2].

Reservoirs in the oil field include Carboniferous marine Donghe sandstone reservoirs and thin sandstone reservoirs in the middle mudstone. The main production layer is the Donghe sandstone at the bottom of the Carboniferous. The Donghe sandstone reservoir is a stratigraphic-structural composite reservoir with a unified temperature-pressure system and tilted oil-water interface. It has a characteristic ultradeep burial depth (more than 5,000 m), a low structural amplitude (less than $34 \mathrm{~m}$ ), a thin and variable reservoir thickness (0-29 m), a large oil-bearing area (superimposed area is about $200 \mathrm{~km}^{2}$ ), a tilted oil-water interface (height difference is greater than $90 \mathrm{~m}$ ), significantly zonal oil properties, and low reserve abundance (less than $30 \times 10^{4} \mathrm{t} / \mathrm{km}^{2}$ in most oil-bearing areas). One hypothesis is that the crude oil originated from paleoreservoirs in the north and that the unconformity between the Carboniferous and Silurian acted as the migration passage [10]. Another is that the oil was probably sourced from the Lower Ordovician through vertical migration along faults [7].

\section{Sampling and Analytical Analysis}

The Donghe sandstone in the Midwestern part of the basin was deposited in the Late Devonian period, but the sandstone in the eastern and northern parts of the basin were deposited in the Early Carboniferous period. The Donghe sandstone is distributed widely in the Hadexun Oilfield with a thickness ranging from $6 \mathrm{~m}$ to $29 \mathrm{~m}$. Samples collected for studying the heterogeneity and clumped isotopes of calcareous interlayers in the Donghe sandstone in Well HD17 in the north and Well HD4 in the south of the Hadexun Oilfield are shown in Figure 2.

The Leica DM 4500P polarizing microscope (Leica, Co., Germany) was used for traditional thin section observation to analyze the composition, texture, and structure of rock and identify rock types, and the CL8200 MK5-1 cathodoluminescence system (CITL Co., United Kingdom), with a working voltage of $15 \mathrm{kV}$ and beam current of $320 \mu \mathrm{A}$, was 


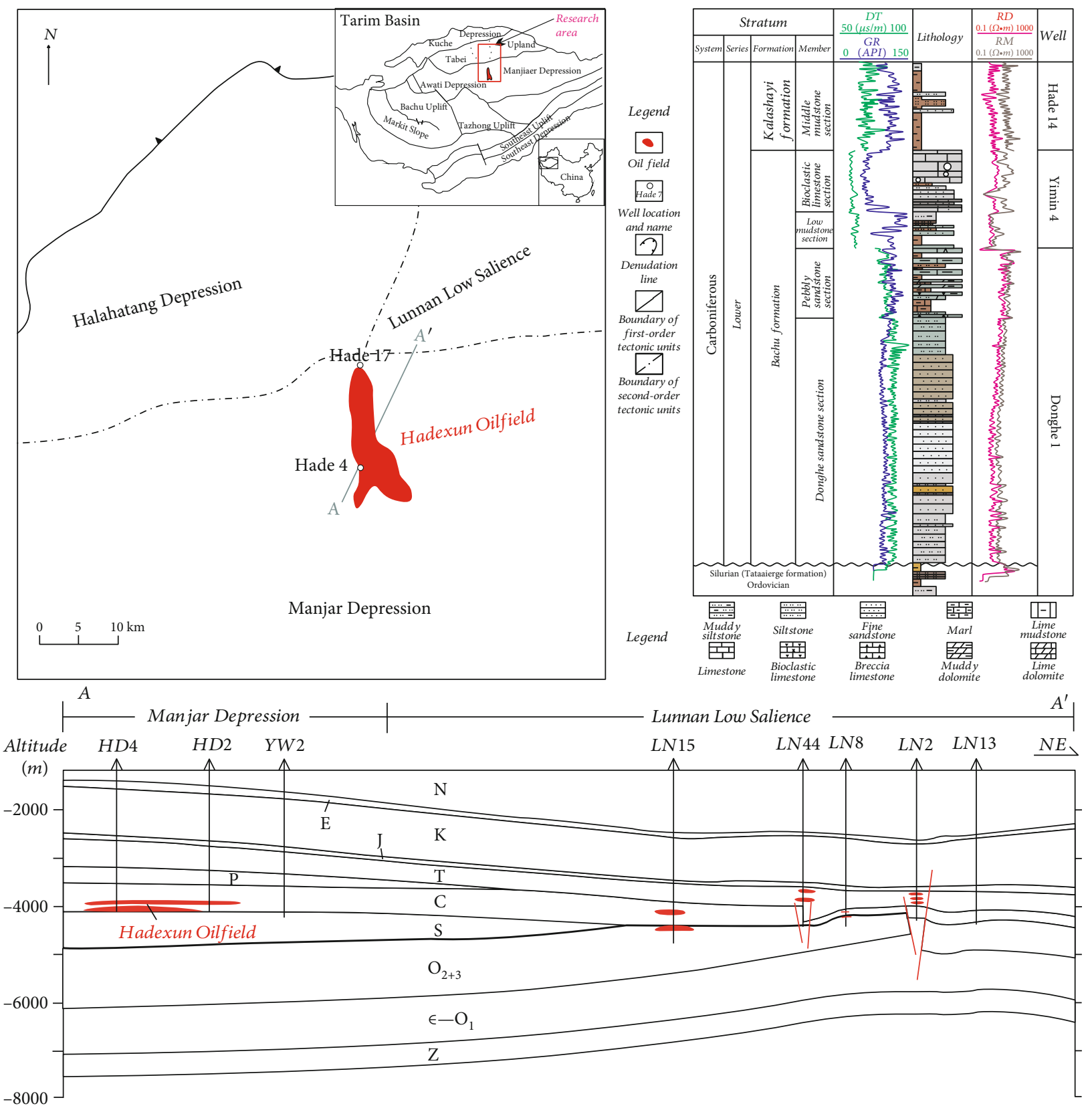

FIGURE 1: Structural location of the Hadexun Oilfield and north-to-south cross-section and reservoir profile of the Hadexun Oilfield-Lunnan Oilfield [2-4].

used for cathodoluminescence analysis. BasinMod 1D (Platte River Associates, USA) was used for basin modeling, where lithology, stratification, terrestrial heat flow, burial depth, and other geological parameters were based on well logging and regional data of the oil field. Whole-rock analysis and clay mineral composition identification were conducted using a TTR diffractometer (Rigaku Electric Corporation, Japan), and the testing conditions were referred from industrial standard No. SY/T 5163-2010. In the whole-rock mineral analysis, 300-mesh-powdered samples were tested after tableting, referring to the $K$ value of the international standard sample, and mass percentages of minerals were calculated by analysis software. The steps required to determine the clay mineral compositions were as follows: (1) extract clay minerals by the suspension method; (2) air-dry oriented thin sections at room temperature and directly test the natural thin section; (3) retest after saturating with glycol at $60^{\circ} \mathrm{C}$ for $8 \mathrm{~h}$; (4) test after heating at $550^{\circ} \mathrm{C}$ for $2.5 \mathrm{~h}$; and (5) calculate the percent content of clay minerals by analysis software.

Clumped isotope analyses were performed using the Thermo 253 IRMS gas source isotope ratio mass spectrometer (Thermo Fisher Scientific, USA) in the California Institute of Technology by the following steps. (1) Sample preparation: the crushed calcareous sandstone sample was immersed in 3\% hydrogen peroxide for $2 \mathrm{~h}$ to ensure removal of organic matter and then dried in an oven at $40^{\circ} \mathrm{C}$ after 


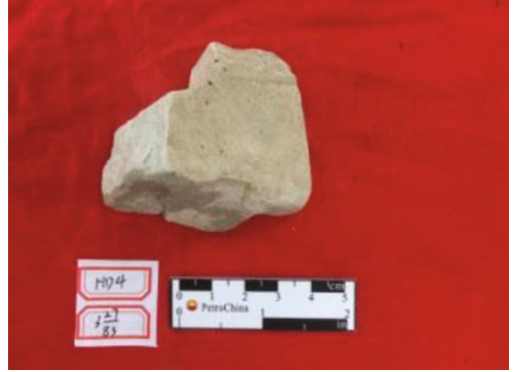

(a) Calcareous interlayer, $5070.07 \mathrm{~m}$, Well HD4

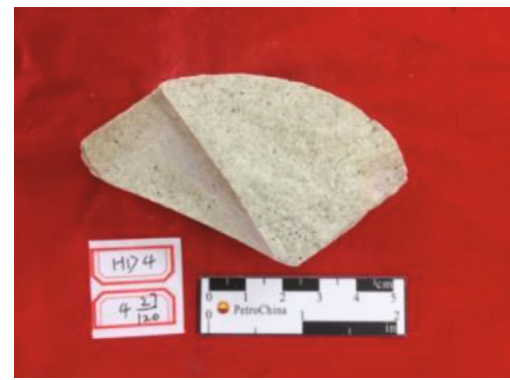

(c) Calcareous interlayer, $52.5098 \mathrm{~m}$, Well HD4

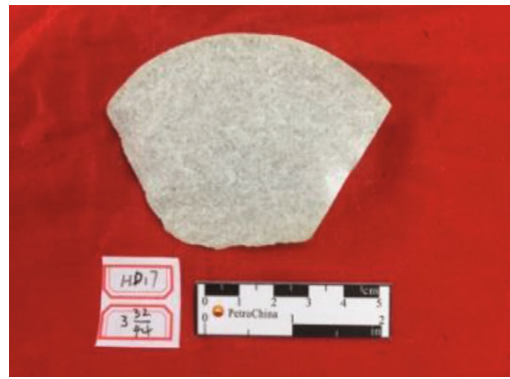

(e) Calcareous interlayer, $5529.47 \mathrm{~m}$, Well HD17

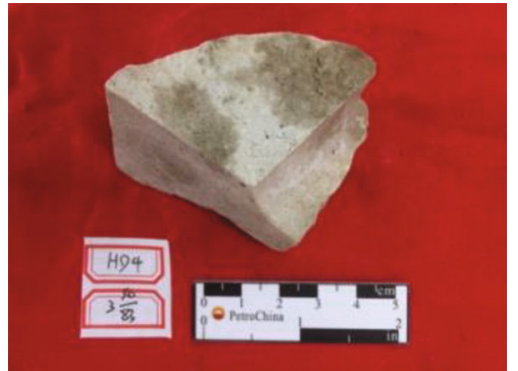

(b) Calcareous interlayer, $5070.62 \mathrm{~m}$, Well HD4

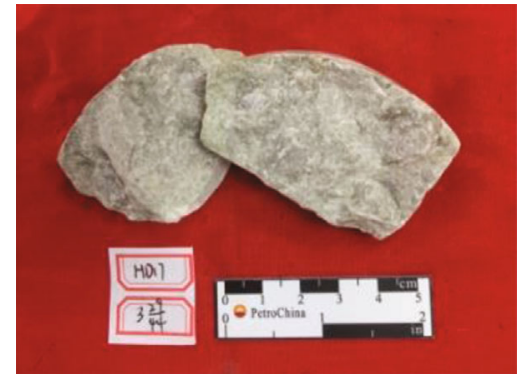

(d) Calcareous interlayer, $5529.01 \mathrm{~m}$, Well HD17

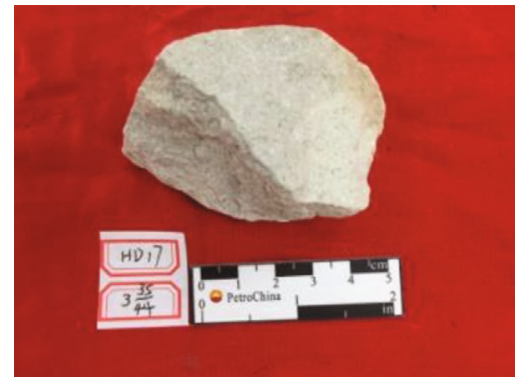

(f) Calcareous interlayer, $5230.13 \mathrm{~m}$, Well HD17

FIgure 2: Photographs with depths of cores sampled from the Hadexun Oilfield.

washing 3-4 times with distilled water. (2) Preparation and purification of $\mathrm{CO}_{2}$ : the $15-20 \mathrm{mg}$ powdered sample was digested in $103 \%$ phosphoric acid at $90^{\circ} \mathrm{C}$ under vacuum for $20 \mathrm{~min}$ in an acid bottle after being conveyed by the automatic sampler when started normally. The generated $\mathrm{CO}_{2}$ was purified on a vacuum line by passing it through dry ice/ethyl alcohol, liquid nitrogen, and a gas chromatography column (GC) to remove water and other pollutants automatically. (3) Measurement of $\Delta 47$ : the purified $\mathrm{CO}_{2}$ gas was passed through the Thermo 253 IRMS gas source isotope ratio mass spectrometer, through which signals of 44-49 $\mathrm{CO}_{2}$ were measured simultaneously. In each measurement, the sample gas and the working gas were tested 7 times alternately, and $\delta^{13} \mathrm{C}, \delta^{18} \mathrm{O}$, and $\Delta 47$ were measured simultaneously. (4) Correction of $\Delta 47$ values: an absolute reference frame (ARF), which standardizes interlaboratory data of clumped isotopes based on theoretical predictions of the abundances of clumped isotopes in gaseous $\mathrm{CO}_{2}$ at thermodynamic equilibrium, was established [31]. Measurements of clumped isotopes of standard gaseous $\mathrm{CO}_{2}$ (break seal) at a reaction temperature of $25-1000^{\circ} \mathrm{C}$ were used for determining slope and intercept by using Package $\mathrm{R}$ [32], and empirical transfer functions were constructed to convert the raw data measured by the mass spectrometer to the absolute reference frame. In addition, the reaction temperature of a sample of carbonate rock should be $25^{\circ} \mathrm{C}$; however, $90^{\circ} \mathrm{C}$ is usually used to increase the reaction rate and thus shorten the reaction time. A high acid solution temperature would result in an isotope fractionation effect; thus, the value of $\Delta 47$ at $25^{\circ} \mathrm{C}$ was necessarily modified by adding $0.092 \%$ [29]. (5) Clumped isotope thermometer: empirical functions applicable to all carbonates at 25$350^{\circ} \mathrm{C}$ were used to transfer the corrected value of $\Delta 47$ to the clumped isotope temperatures using the following equation: $\Delta 47, \mathrm{ARF}=0.0428 \times 10^{6} / \mathrm{T}^{2}+0.1174[33]$.

\section{Results}

4.1. Petrological Features and Mineral Composition of Calcareous Sandstone. The content of carbonate cements in the Donghe sandstone varies greatly. As shown in Figure 3, the content approaches zero in sandstone in which the hydrocarbon emplacement occurred, suggesting an inhibitory effect of the hydrocarbon emplacement to carbonate cementation. The results of the mineral composition analysis, which were precisely consistent with those of the 


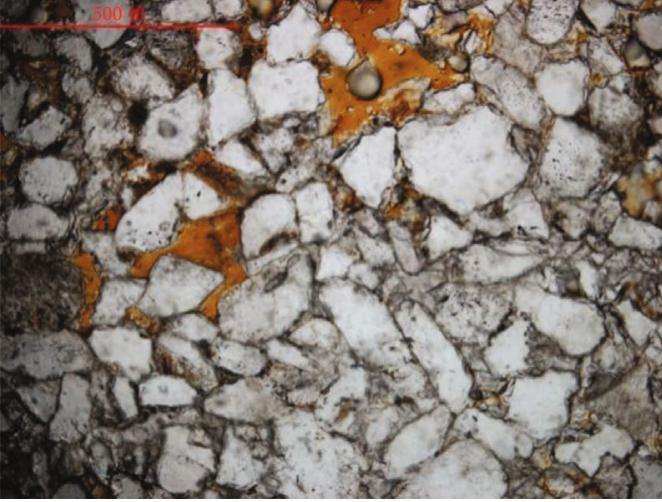

(a) Oil-bearing and oil-free sandstones, $5070.07 \mathrm{~m}$, polarizing microscope with plane-polarized light, Well HD4

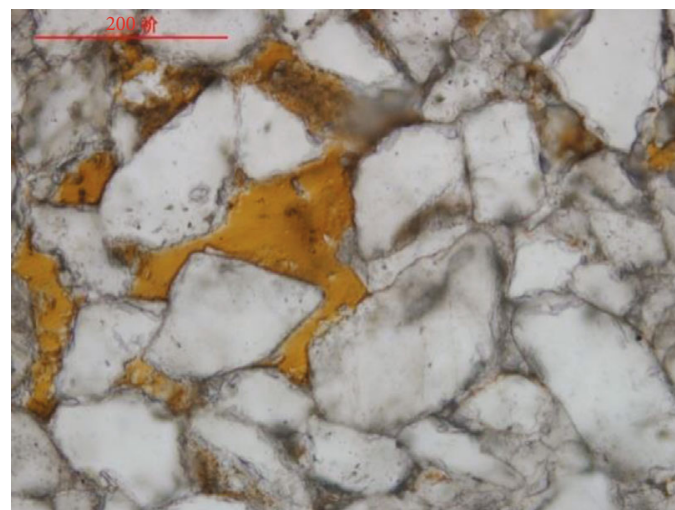

(c) Oil-bearing and oil-free sandstones, $5070.07 \mathrm{~m}$,

polarizing microscope with plane-polarized light, Well HD4

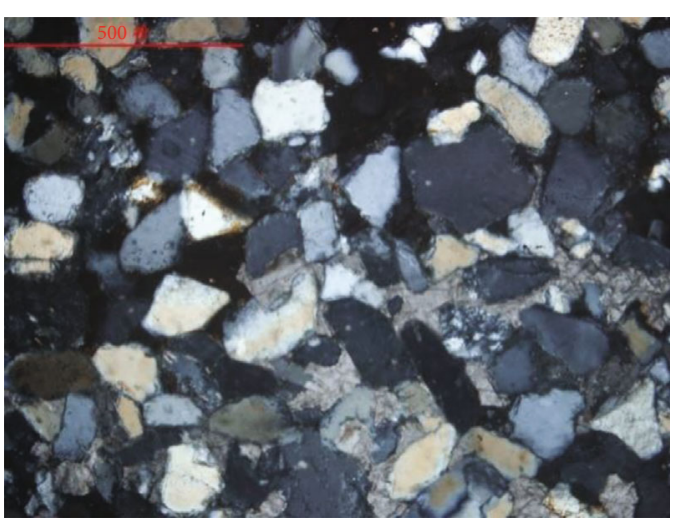

(b) Oil-bearing and oil-free sandstones, $5070.07 \mathrm{~m}$, polarizing microscope with cross-polarized light, Well HD4

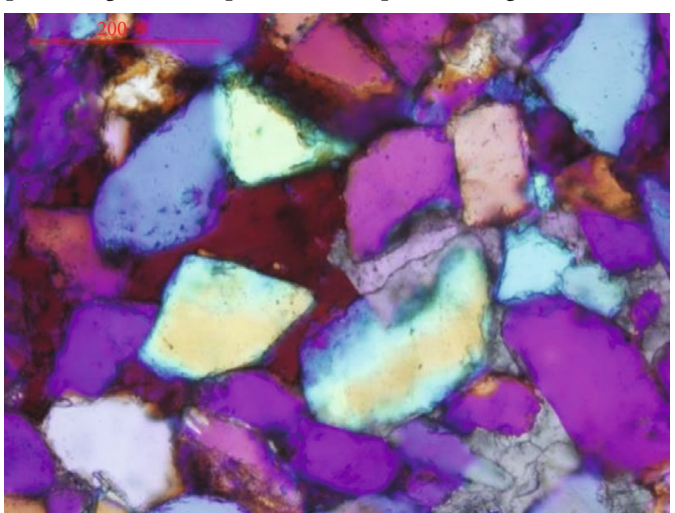

(d) Oil-bearing and oil-free sandstones, $5070.07 \mathrm{~m}$,

polarizing microscope with crossed $+\lambda$ polarized light

FIgURE 3: Distribution of the pores and cements in calcareous sandstones of Hadexun Oilfield.

microscopic thin section analysis, indicated that the calcareous cements are dominated by calcite, which has contents as high as $26.9-73.5 \%$ and attains a content of $94.8 \%$ in the limestone samples, as listed in Table 1.

In Well HD4 in the south, the sandstones developed in calcareous interlayers within the Donghe sandstone are predominantly lithic quartz sandstone or feldspathic lithic sandstone, with medium-fine granular or inequigranular and subrounded clastics, the long axes of which are slightly directional. The clastics are mainly quartz, followed by lithic fragments and feldspar, and the reservoir cements have relatively high contents of calcite, which occurs as clots or poikilitic cements. The pores are mainly intergranular pores, and according to the physical properties, the sandstones are classified as having low porosity and low permeability.

In Well HD17, the sandstones are dominantly lithic quartz sandstone, with fine to very fine, subangular to subrounded clastics that are arranged with slight directionality. As shown in Figure 4, the clastics are mainly quartz, followed by lithic fragments and feldspar, and the reservoir cements have a relatively high content of calcite, which occurs as poikilitic cement, and rare ankerite. The pores are mainly intergranular pores, and the sandstones are low-porosity and low-permeability sandstones. The differences of clastic content and grain size between the northern and southern
Hadexun area indicate the possibility of different provenances in the two wells.

\subsection{Cathodoluminescence Characteristics of Calcareous} Sandstone. In this study, three phases of cement were identified by cathodoluminescence and electron microprobe analyses. Phase I carbonate cements consist of nonluminescent $\mathrm{Fe}$-free and $\mathrm{Mg}$-free calcites, fill space between clastic particles, often occur as crystal stocks or lamellar crystals, and are spatially distributed between particles with loose or no contact. This indicates that the cements formed in the exposure or shallow burial stage (early diagenetic phase A), when the compaction of particles was very weak. When exposed to cathodoluminescence for a properly increased period, the cements fluoresce light orange-yellow (Figures 5(a) and 5(b)), which appears only in some samples with low cement content.

The main compositions of carbonate cements of phases II and III are calcites, which fluoresce orange-red or orangeyellow. Phase II carbonate cements surround quartz grains and show orange-red cathodoluminescence. Phase III carbonate cements grew in the middle of pores, which are the principal locale for the cement, and show bright-orange cathodoluminescence (Figures 5(c)-5(d)). These two phases of cements have distinctly different spatial locations from the 
TABLE 1: Mineral components in calcareous interlayers within the Donghe sandstone, Hadexun Oilfield, based on XDR whole-rock analysis.

\begin{tabular}{lcccccccc}
\hline \multirow{2}{*}{ Well no. } & \multirow{2}{*}{ Depth/m } & \multirow{2}{*}{ Lithology } & \multicolumn{4}{c}{ Type and content (\%) of minerals } & \multicolumn{2}{c}{ Total content of } \\
& & & Quartz & K-feldspar & Calcite & Pyrite & Dolomite & clay minerals (\%) \\
\hline HD4 & 5070.07 & Sandstone & 68.0 & 1.9 & 26.9 & - & - & - \\
HD4 & 5070.62 & Sandstone & 54.9 & 1.4 & 39.9 & - & - & - \\
HD4 & 5098.52 & Sandstone & 20.9 & 2.8 & 73.5 & - & - & - \\
HD17 & 5529.01 & Sandstone & 4.4 & 0.8 & 94.8 & - & - & - \\
HD17 & 5529.47 & Sandstone & 42.6 & 1.8 & 52.8 & - & 5.8 \\
HD17 & 5230.13 & Sandstone & 54.0 & 1.9 & 36.2 & 0.9 & 5.4 & 1.6 \\
\hline
\end{tabular}

location of phase I cements, which formed mainly between particles with spot-line contacts, indicating that they formed in the shallow burial stage (early diagenetic phase B).

\subsection{Oxygen and Carbon Isotopes and $\Delta 47$ in Calcareous} Cement. Carbon and oxygen isotopic analysis of a reservoir is an effective method to study the origin of carbonate cements. This study analyzed the carbon and oxygen isotope data of six samples of carbonate cement in the work area. The isotope ratios were reported relative to the Pee Dee Belemnite (PDB) standard, and the accuracy of the isotope measurement was less than $0.03 \%$. In the Donghe sandstone in Well HD4 in the southern part of the Hadexun area, the average $\delta^{13} \mathrm{C}_{\mathrm{PDB}}$ values of carbonate cements from five measurements ranged from $-4.4 \%$ to $-3.1 \%$, and the average $\delta^{18} \mathrm{O}_{\mathrm{PDB}}$ values ranged between $-10.6 \%$ and-6.9\%o. In the Donghe sandstone in Well HD17 in the northern part of the area, the average $\delta^{13} \mathrm{C}_{\mathrm{PDB}}$ values of carbonate cements from five measurements ranged from $-7.8 \%$ o to $-4.5 \%$, and the average $\delta^{18} \mathrm{O}_{\mathrm{PDB}}$ values ranged between $-9.8 \%$ and $6.9 \%$ (Table 2). The measurements showed that the apparent $\Delta 47$ values of the calcareous cements range from 0.545 to 0.590 in Well HD17 in the northern part of the Hadexun area and between 0.546 and 0.572 in Well HD4 in the southern part of the Hadexun area.

\section{Discussion}

5.1. Oil Heterogeneity of Donghe Sandstone and Its Control Factors. A comparison between the mineral compositions and diagenetic characteristics of oil-bearing and oil-free sandstones suggests that calcareous cementation is the major cause of the porosity reduction in the sandstone and that it also results in the oil-bearing heterogeneity in the generated tight sandstones (Figure 3). In the sandstones in the Hadexun Oilfield without calcareous cement, pores in the reservoir rocks are mainly intergranular dissolution pores. The main reservoirs have medium porosity, ranging between $12.5 \%$ and $20 \%$, with an average of $13.8 \%$, and medium-high permeability, ranging from 50 to $1000 \times 10^{-3} \mu \mathrm{m}^{2}$, with an average of $222 \times 10^{-3} \mu \mathrm{m}^{2}$. The calcareous interlayers in the Donghe sandstone in the Hadexun Oilfield are higher than those in the Donghetang Oilfield, which is located in the northwest with calcite content averaging 10\% [8]. The porosity of calcareous sandstone ranges between $5.1 \%$ and $7.3 \%$, with an average of $6 \%$.
The carbon isotope values of the calcareous cements analyzed are within the range of those of carbonates of freshwater origin, which range from $-5 \%$ o to $-1 \%$. The previous carbon isotope analyses of calcareous cements in the Donghe sandstone also indicated a freshwater origin and a relation to organic carbon dissolution in only a few samples [34, 35]. According to the carbon and oxygen isotope chart shown in Figure 6, only two cements of the Donghe sandstone in the Hadexun area lie in the freshwater calcite area, and the rest are within the diagenetic calcite area $[14,36]$. However, this result is not consistent with previous results showing that the calcareous cements are of epigenetic and syngenetic freshwater origin, which was confirmed by petrologic features and microscopic analysis of mineral cements $[12,14,16,17]$. The $Z$ value, which can be used to determine the genetic types of calcareous cements, is calculated by the empirical formula $Z=2.048 \times\left(\delta^{13} \mathrm{C}_{\mathrm{PDB}}+50\right)+0.498 \times$ $\left(\delta^{18} \mathrm{O}_{\mathrm{PDB}}+50\right)$. When the $Z$ value is greater than 120 , it indicates marine cements; when the value is less than 120 , it indicates freshwater cements [37]. According to calculations using the carbon and oxygen isotope results of the analyzed cements of the Hedong sandstone in the Hadexun area (Table 3 ), the $Z$ values of calcareous cements in both Well HD4 and Well HD17 are less than 120, indicating that the cements are freshwater carbonate cements influenced by meteoric freshwater.

A previous study of the Donghe sandstone in adjacent areas reported that carbonate cements were one of the main factors controlling hydrocarbon accumulation and that the reservoir quality often depended on their content and distribution [1]. In recent years, some scholars have suggested that the sequence stratigraphy played a controlling role in the diagenetic process, that carbonate cementation tended to occur in the early development stage of the transgressive system tract and high-stand system tract, and that cementation did not occur easily in the late development stage of the low-stand system tract and the high-stand system tract $[12,16,17]$. The role of depositional facies and sequence stratigraphy impacts the diagenesis and the heterogeneity of sandstone reservoirs $[18,19]$. Horizontally, the physical properties of the Donghe sandstone reservoirs are relatively poor near the pinch-out boundary but significantly better far from it, showing a variation trend as a whole that is favorable in the south but slightly poor in the north [38].

5.2. Diagenetic Stage and Genesis of Calcareous Sandstone. Some scholars have reported that the carbonate cements are 


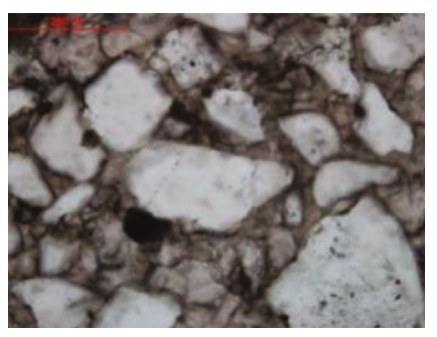

(a) Oil-free sandstones, $5070.62 \mathrm{~m}$, polarizing microscope with plane-polarized light, Well HD4

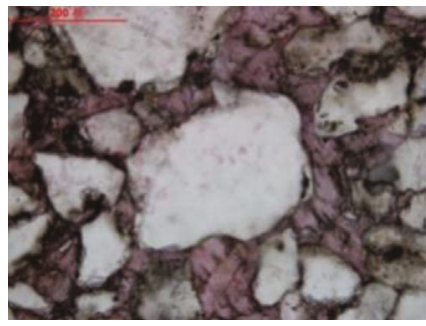

(c) Oil-free sandstones, $5070.62 \mathrm{~m}$, polarizing microscope with plane-polarized light, Well HD4

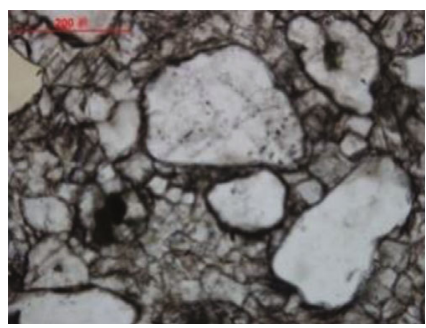

(e) Oil-free sandstones, $5098.52 \mathrm{~m}$, polarizing microscope with plane-polarized light, Well HD4

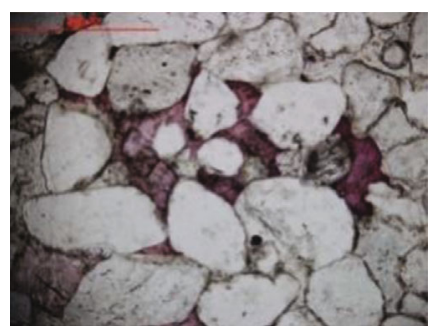

(g) Oil-free sandstones, $5098.52 \mathrm{~m}$, polarizing microscope with plane-polarized light, Well HD4

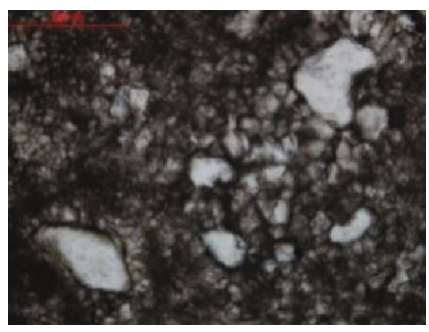

(i) Oil-free sandstones, $5529.01 \mathrm{~m}$, polarizing microscope with plane-polarized light, Well HD17

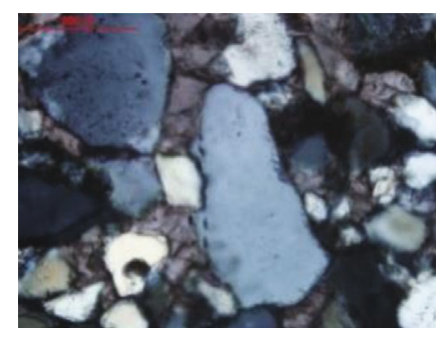

(b) Oil-free sandstones, $5070.62 \mathrm{~m}$, polarizing microscope with cross-polarized light, Well HD4

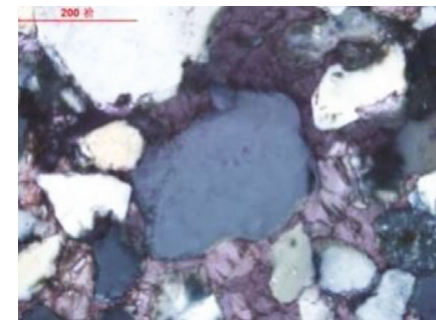

(d) Oil-free sandstones, $5070.62 \mathrm{~m}$, polarizing microscope with cross-polarized light, Well HD4

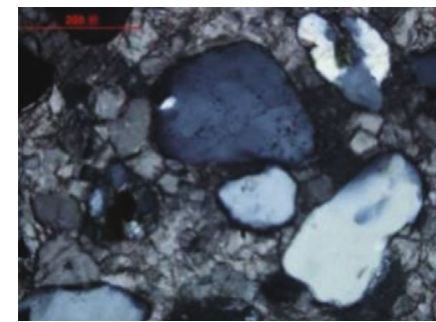

(f) Oil-free sandstones, $5098.52 \mathrm{~m}$, polarizing microscope with cross-polarized light, Well HD4

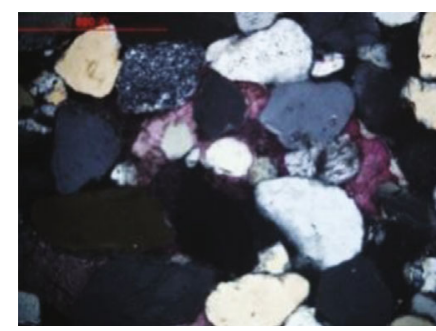

(h) Oil-free sandstones, $5098.52 \mathrm{~m}$, polarizing microscope with cross-polarized light, Well HD4

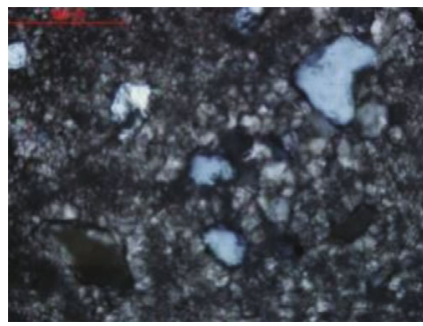

(j) Oil-free sandstones, $5529.01 \mathrm{~m}$, polarizing microscope with cross-polarized light, Well HD17

Figure 4: Continued. 


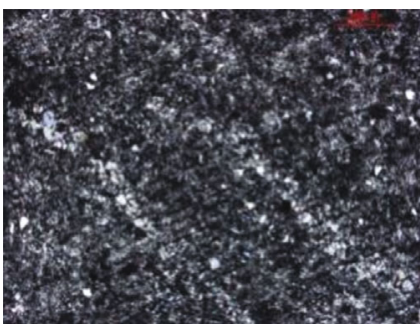

(k) Oil-free sandstones, $5529.01 \mathrm{~m}$, polarizing microscope with plane-polarized light, Well HD17

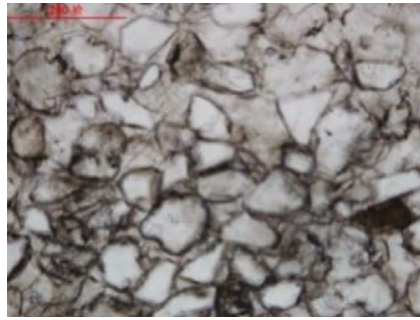

(m) Oil-free sandstones, $5529.47 \mathrm{~m}$, polarizing microscope with plane-polarized light, Well HD17

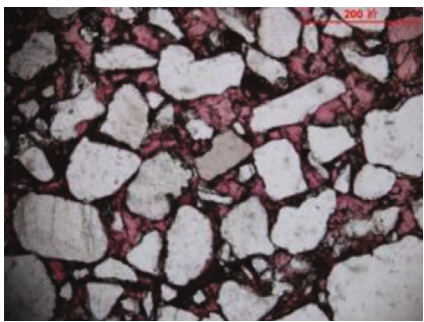

(o) Oil-free sandstones, $5230.13 \mathrm{~m}$, polarizing microscope with plane-polarized light, Well HD17

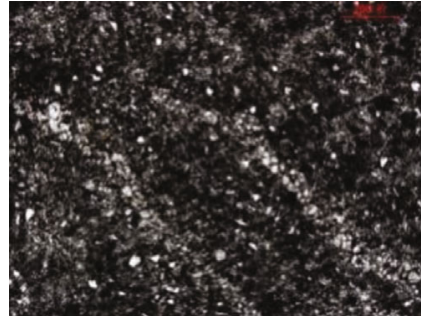

(1) Oil-free sandstones, $5529.01 \mathrm{~m}$, polarizing microscope with cross-polarized light, Well HD17

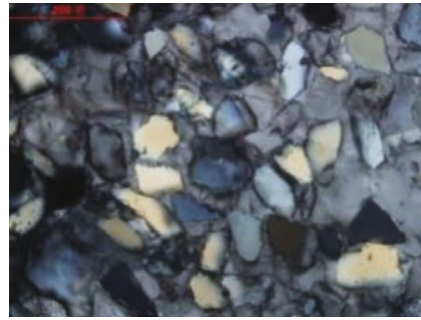

(n) Oil-free sandstones, $5529.47 \mathrm{~m}$, polarizing microscope with cross-polarized light, Well HD47

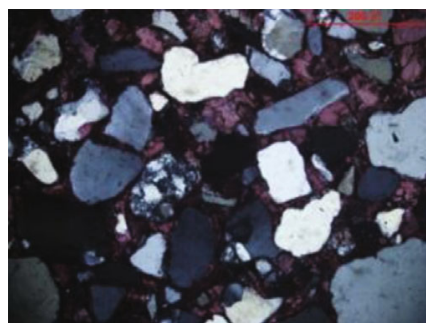

(p) Oil-bearing and oil-free sandstones, $5230.13 \mathrm{~m}$, polarizing microscope with cross-polarized light, Well HD13

Figure 4: Typical characteristics of calcareous interlayers in the Hadexun Oilfield under a polarizing microscope with plane-polarized light and cross-polarized light.

composed mainly of massive and crystal-stock calcites formed at the early stage of diagenesis, which account for 94\% of the carbonate cements. The calcareous interlayers are mainly dependent on the carbonate cementation that occurred at the early stage of diagenesis, and the phase I carbonate cements are similar to calcite cements precipitated from seawater in shallow oxidizing conditions, where the calcium is sourced from the sea [8]. Other scholars have analyzed the proportions of carbonate cements of different phases and concluded that the carbonate cements are precisely dominated by phase I calcites, which account for more than $83 \%$ of the total carbonate cements. However, their formation environment was reported as a meteoric freshwater environment in the hypergene condition $[16,17]$. Nevertheless, phase II and III carbonate cements were found in most of the samples used in this experiment. It was reported that the nonluminous carbonate of phase I would have dissolved in the subsequent diagenetic stage, which provided material for the phase II and III carbonate cements. A comparison of major elements (iron and manganese) of cements of the various phases identified microscopically using the electron microprobe demonstrated significantly higher contents of $\mathrm{Mn}$ in the phase II and III cements. The average contents of $\mathrm{Mn}$ and Fe are $2142 \times 10^{-6}$ and $414 \times 10^{-6}[8,10]$. The sig- nificant difference of $\mathrm{Fe}$ and $\mathrm{Mn}$ contents in the carbonate cements of the different phases indicates that they formed in different diagenetic stages, which confirms the cement phases identified microscopically in this experiment.

Previous studies also identified phase IV carbonate cements, which are composed mainly of ferruginous calcite and ferruginous dolomite, show nonluminescence or dark orange-red cathodoluminescence, and are typically characterized by replacement of feldspar grains $[8,13]$. Complete replacement of feldspar grains is observed, indicating that the phase IV carbonate cements formed in the middle burial stage (middle diagenetic phase A) [8, 10]. However, no obvious phase IV carbonate cement was observed in this experiment, and minor dolomite was detected only in the samples at $5230.13 \mathrm{~m}$ in Well HD17 (Table 1).

The diagenetic process can be described as follows. With an increase of burial depth, the space between grains was reduced under the influence of compaction, resulting in a change of grain contacts from point contacts to line contacts. Thus, a semiclosed or nearly closed diagenetic environment formed. Communication with external fluids was limited, and the reducibility of the diagenetic environment was enhanced subsequently. As a result, the phase II and III carbonate cements have higher contents of iron and manganese 


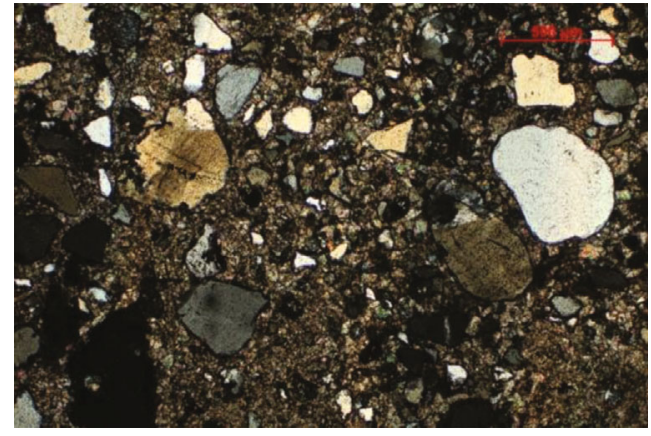

(a) Calcite-cemented sandstones, $5098.52 \mathrm{~m}$, polarizing microscope with cross-polarized light, Well HD4

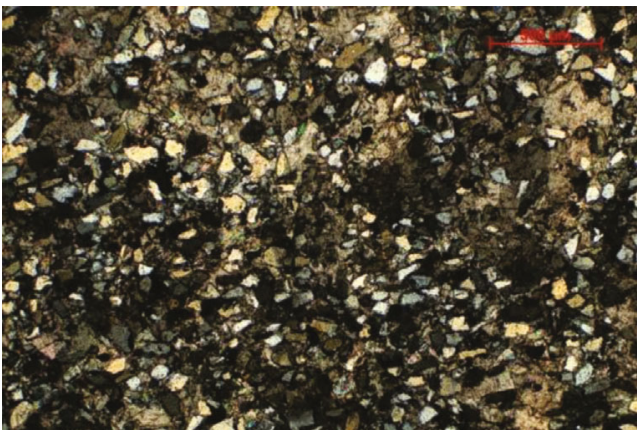

(c) Calcite-cemented sandstones, $5529.47 \mathrm{~m}$, polarizing microscope with cross-polarized light, Well HD17

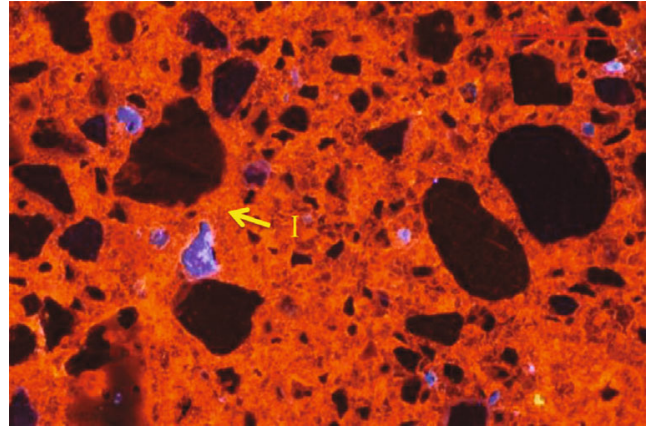

(b) Calcite-cemented sandstones, $5098.52 \mathrm{~m}$, cathodoluminescence, Well HD4

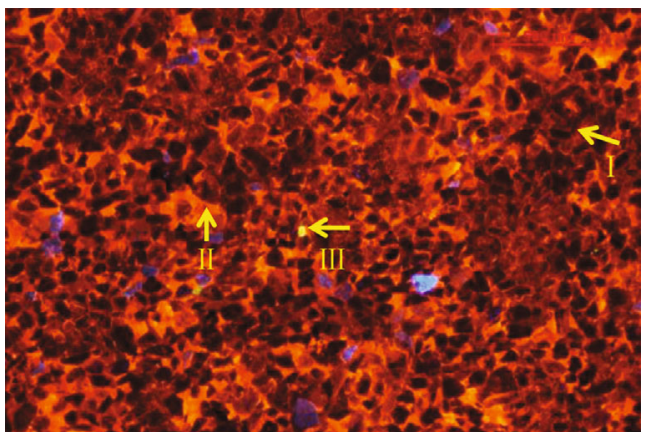

(d) Calcite-cemented sandstones, $5529.47 \mathrm{~m}$, cathodoluminescence, Well HD17

FIGURE 5: Typical cathodoluminescence images of calcareous cements.

TABle 2: Percentages of cements of different phases in calcareous interlayers within the Donghe sandstone, Hadexun Oilfield.

\begin{tabular}{|c|c|c|c|c|c|}
\hline \multirow{2}{*}{ Well no. } & \multirow{2}{*}{ Depth/m } & \multirow{2}{*}{ Lithology } & \multicolumn{3}{|c|}{ Percentage of cements of different phases $/ \%$} \\
\hline & & & Phase I & Phase II & Phase III \\
\hline Well HD4 & 5070.07 & Sandstone & & 81.8 & 18.2 \\
\hline Well HD4 & 5070.62 & Sandstone & & 73.3 & 26.7 \\
\hline Well HD4 & 5098.52 & Sandstone & 0.8 & 50.1 & 49.1 \\
\hline Well HD17 & 5529.01 & Sandstone & & 55.3 & 44.7 \\
\hline Well HD17 & 5529.47 & Sandstone & & 49.9 & 50.1 \\
\hline Well HD17 & 5230.13 & Sandstone & & 60.1 & 39.9 \\
\hline
\end{tabular}

and show a bright color under the cathodoluminescence microscope [8]. The source of the calcium in the calcareous cements of the Donghe sandstone in the Hadexun area remains controversial. Some scholars believed that the calcium was probably derived from feldspar or lithic fragments dissolved by fresh water. However, it was also considered that feldspar contributed little to the carbonate cementation because of its extremely low content in this area and that the Lunnan bulge was uplifted from the middle Late Ordovician to Early Triassic, resulting in the erosion of a large number of carbonate strata. Thus, the calcium would have been derived from the washing and dissolution of the carbonate clasts from the Lunnan low bulge by seawater, which provided abundant carbonate in solution $[8,39]$.

5.3. The Formation Temperature of Calcareous Cementation in Calcareous Sandstone. Oxygen isotope analysis is useful for determining the origin of cement, and it can be used for predicting the cement's formation temperature. For example, according to the well-known formula of a geothermometer for carbonate rock, $T=16.9-4.38 \times\left(\delta^{18} \mathrm{O}_{\text {carbonate }}-\right.$ $\left.\delta^{18} \mathrm{O}_{\text {water }}\right)+0.10 \times\left(\delta^{18} \mathrm{O}_{\text {carbonate }}-\delta^{18} \mathrm{O}_{\text {water }}\right)^{2}$, the formation temperature can be calculated based on the oxygen isotope values of carbonate and water. However, the biggest problem with this method is how to obtain the $\delta^{18} \mathrm{O}$ value of the water in the diagenetic period $[40,41]$. Some scholars have proposed that the $\delta^{18} \mathrm{O}$ value of the formation water of the Donghe sandstone was close to that of continental fresh water. Thus, considering that the $\delta^{18} \mathrm{O}$ value of continental fresh water generally ranges between $-20 \%$ and $-6 \%$ (SMOW), the isotopic value of the formation water in the Donghe sandstone was taken as $-10 \%$ and the formation temperature of carbonate cement was calculated correspondingly as $7.7-36.5^{\circ} \mathrm{C}[12]$. 


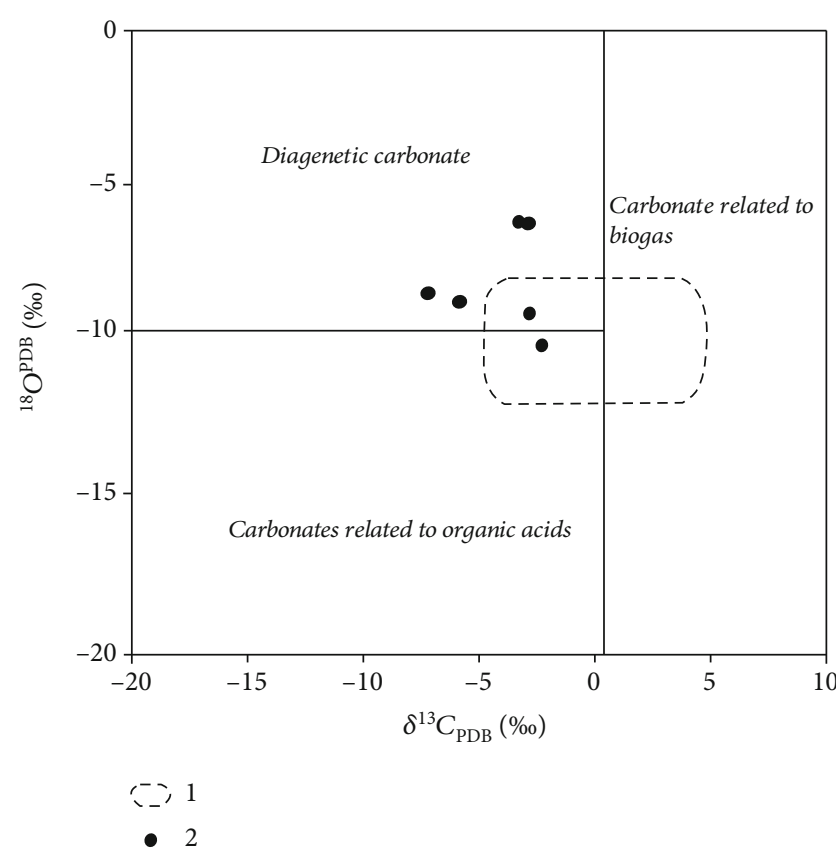

Figure 6: Determination of origin of carbonate cements based on the correlation of carbon and oxygen isotopes. (1) Dotted line: fresh water calcite area (after [36]). (2) Donghe Sandstone in Hadeson Oilfield.

Additionally, how to determine the exact formation time of calcareous cement has become a great problem in diagenetic research. The abundance of isotopologue ${ }^{13} \mathrm{C}^{18} \mathrm{O}^{16} \mathrm{O}$ $(\Delta 47)$ in carbonates is sensitive to the growth temperature of the minerals and independent of the fluids (waters) from which the carbonates grew. The $\Delta 47$ value can be calculated from equation (1) below, where $R 47$ is the abundance ratio of mass 47 relative to mass 44 of $\mathrm{CO}_{2}$ in the sample and $R * 47$ is the corresponding ratio of mass 47 relative to mass 44 that would occur in the sample if it had a stochastic distribution $[20,21]$. It is worth pointing out that the measured apparent $\Delta 47$ values of the calcareous cements are essentially average values of cements of multiple phases.

$$
\Delta 47=\left(\frac{R_{47}}{R * 47}-1\right) \times 1000(\% \text { o }) .
$$

In this experiment, calcareous cements were detected in the calcareous interlayers. Statistical analysis of the calcareous cements of the different phases detected from cathodoluminescence images was performed using Avzaon, and the result showed that the relative contents of carbonate cements of different phases varied significantly among different samples (Table 2). This is possibly a result of the mixing of meteoric fresh water and seawater in pores in the sandstones of the wave-controlled, delta-shore sedimentary system and subsequent diagenetic differences. According to the proportions of cements of different phases (Table 2), the true $\Delta 47$ values of each phase can be calculated by solving equations in the multiple variables. Considering the dominance of the two phases of cements, the $\Delta 47$ values of the phase II and III calcareous cements in calcareous interlayers of the Donghe sandstone were represented by $\Delta 47_{\mathrm{II}}$ and $\Delta 47_{\mathrm{III}}$, and their proportions in sample $i$ were defined as $a_{i} \%$ and $b_{i} \%$, respectively. To calculate the unknown $\Delta 47_{\text {II }}$ and $\Delta 47_{\text {III }}$, the number of linear equations required has to be greater than or equal (equation (2)) to the number of phases of cements ( $i \geq 2$ in this case). According to Tables 2 and 3 , the calculated values of $\Delta 47_{\text {II }}$ and $\Delta 47_{\text {III }}$ are $0.610-0.620$ and $0.492-0.520$, respectively.

$$
\left\{\begin{array}{l}
\Delta 47_{1}=\Delta 47 I I \times a_{1} \%+\Delta 47 I I I \times b_{1} \%, \\
\Delta 47_{2}=\Delta 47 I I \times a_{2} \%+\Delta 47 I I I \times b_{2} \% .
\end{array}\right.
$$

In fact, the determination of the dependence between $\Delta 47$ and temperature is influenced by a variety of factors, including the settling rate of carbonates, the $\mathrm{pH}$ value of geological fluids, and the ionic strength [42]. Fortunately, in recent years, a large amount of research has focused on the equations between $\Delta 47$ and temperature $(T)$, and attempts have been made to reduce the uncertainties related to different dissolution rates of carbonates, the variety of carbonate rocks, and different laboratory measurements through standardization [43]. The apparent formation temperatures corresponding to the apparent $\Delta 47$ values of the calcareous interlayers in Well HD4 in the southern area range from 53.7 to $71.6^{\circ} \mathrm{C}$, and those in Well HD17 in the northern area range from 64.0 to $71^{\circ} \mathrm{C}$. The formation temperatures calculated by the end-member method are $41.0-45.1^{\circ} \mathrm{C}$ and $89.2-$ $94^{\circ} \mathrm{C}$, respectively. These were calculated according to the internationally published calibration equation of $\Delta 47$ and temperature (Figure 7). It should be noted that the temperatures calculated from the previous calibration curves of $\Delta 47$ and temperature are $45-50^{\circ} \mathrm{C}$ and $90-100^{\circ} \mathrm{C}$, respectively [28, 44-48].

5.4. Diagenetic Process of Calcareous Cementation in Calcareous Sandstone. The calcareous cements were apparently identified as the products of the early diagenetic period in this paper, but they actually should be classified as the products of early diagenetic stage A and early diagenetic stage $\mathrm{B}$, according to formation temperature and diagenetic stage division $[49,50]$. According to the burial and thermal histories, the formation temperature of the phase II carbonate cements indicates that they developed in the Middle Permian period, and their formation is speculated to be related to the shallow burial and tectonic uplift during the Hercynian period. The phase III carbonate cements are suggested to have developed in the Early Neogene period, which is speculatively related to rapid burial. The specific diagenetic process can be described as follows. With increase of burial depth, the space between particles was reduced by compaction, resulting in a change of grain contacts from point contacts to line contacts. Thus, a semiclosed or nearly closed diagenetic environment was formed. The limited communication with external fluids enhanced the reducibility of the subsequent diagenetic environment. As a result, the phase III carbonate cements, which show a relatively bright color under the cathodoluminescence microscope, were developed [8]. 
TABle 3: Carbon and oxygen isotopes, $\Delta 47$, and calculated $Z$ values of calcareous cement in the Donghe sandstone, Hadexun Oilfield.

\begin{tabular}{lccccccccccc}
\hline Well & Depth $(\mathrm{m})$ & No. $^{1}$ & $\delta^{13} \mathrm{C}(\% \text { o })^{2}$ & 1 s.d. ${ }^{3}$ & $\delta^{18} \mathrm{O}(\% \text { o })^{4}$ & 1 s.d. ${ }^{5}$ & $\Delta 47$ avg $^{6}$ & 1 s.e. $^{7}$ & $\delta^{18} \mathrm{O}\left(\%\right.$ o $^{8}$ & 1 s.d. ${ }^{9}$ & $Z$ value $^{10}$ \\
\hline HD4 & 5070.07 & 5 & -3.1 & 0.1 & -10.6 & 0.1 & 0.590 & 0.021 & -3.1 & 2.8 & 115.7 \\
HD4 & 5070.62 & 5 & -3.3 & 0.1 & -9.8 & 0.3 & 0.580 & 0.015 & -1.6 & 2.4 & 115.7 \\
HD4 & 5098.52 & 5 & -4.4 & 0.0 & -6.9 & 0.1 & 0.545 & 0.005 & 3.6 & 0.8 & 114.8 \\
HD17 & 5529.01 & 5 & -4.5 & 0.0 & -6.9 & 0.1 & 0.562 & 0.005 & 2.4 & 0.6 & 114.7 \\
HD17 & 5529.47 & 5 & -7.8 & 0.1 & -9.0 & 0.1 & 0.546 & 0.020 & 1.4 & 0.8 & 106.9 \\
HD17 & 5230.13 & 5 & -5.6 & 0.1 & -9.8 & 0.1 & 0.572 & 0.015 & -1.1 & 0.6 & 111.0 \\
\hline
\end{tabular}

${ }^{1}$ Number of replicate runs. ${ }^{2} \mathrm{The} \delta^{13} \mathrm{C}(\%)$ value is the average value of five replicates and output by PDB. ${ }^{3}$ Standard deviation of $\delta^{13} \mathrm{C} .{ }^{4} \mathrm{The} \delta^{18} \mathrm{O}(\%)$ value is the average value of five replicates and output by PDB. ${ }^{5}$ Standard deviation of $\delta^{18} \mathrm{O} .{ }^{6} \Delta 47$ avg. is the average value of five replicates. ${ }^{7}$ Standard errors of regression coefficients of the $e \Delta 47 .{ }^{8} \delta^{18} \mathrm{O}(\%)$ is the average calculated value of the water and output by SMOW. ${ }^{9} 1$ s.d. is the standard deviation of $\delta^{18} \mathrm{O}$.

${ }^{10}$ The $Z$ value was calculated using the formula $Z=2.048 \times\left(\delta^{13} \mathrm{C}_{\mathrm{PDB}}+50\right)+0.498 \times\left(\delta^{18} \mathrm{O}_{\mathrm{PDB}}+50\right)$ after Keith et al. [37].

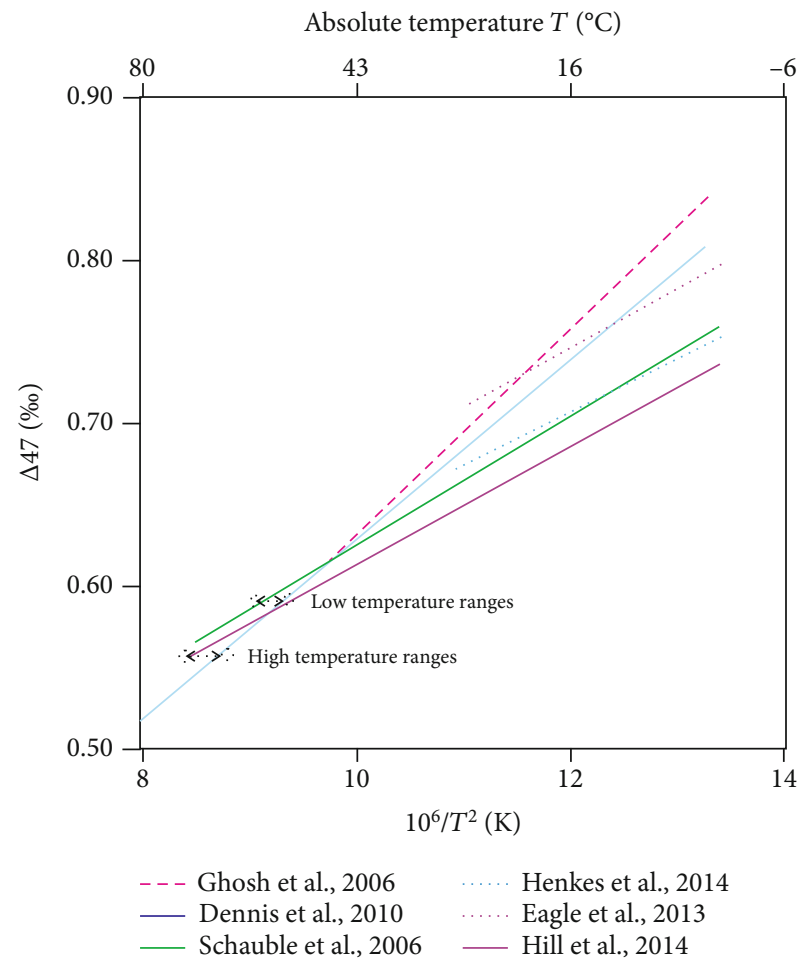

Figure 7: Carbonate cement $\Delta 47$ and absolute temperature in some typical calculating formulas.

The analyses of the formation temperatures calculated from $\Delta 47$ of the cements in the two wells in the Hadexun Oilfield indicate slightly higher formation temperature in Well HD17 in the northern region than in Well HD4 in the south, indicating that the time of diagenesis was earlier in Well HD4. The consistency of the highest formation temperature in these two wells reflects the same diagenetic process experienced by the Donghe sandstones in the early burial stage at the southern and northern parts of the Hadexun Oilfield. In fact, unconformities are developed at the top and bottom of the Donghe sandstones in the south and the north, and the overlying and underlying strata also effectively support the conclusion that the northern and southern parts of the Hadexun Oilfield had the same overall diagenetic process.

In recent years, many scholars have found that the information of carbonate clumped isotopes could change with increasing formation temperature under certain conditions; however, it can be predicted quantitatively by corresponding models $[29,30]$. In fact, from the end of the Silurian to the end of the Paleogene (380 Ma) in the Hadexun Oilfield, the burial depth of the Donghe sandstone was always less than $2700 \mathrm{~m}$ and the ground temperature was lower than $85^{\circ} \mathrm{C}$. The sedimentation rate was as low as $7.03 \mathrm{~m} / \mathrm{Myr}$, and the compaction was weak, suggesting that the Donghe sandstone was in the early diagenetic stage during this period, when carbonate cements and secondary enlargements of quartz, kaolinite, and other clay minerals were predominately developed; dissolution of a small amount of feldspars and lithic particles occurred; and primary pores were preserved. Upon entering a temporary rapid burial stage in the Neogene, the burial depth of the Donghe sandstone in the study area was close to $6000 \mathrm{~m}$, and the diagenesis progressed into the middle diagenetic stage.

The carbonate cements that had formed earlier were dissolved, clay minerals such as illite and chlorite were formed, and iron-bearing carbonates were eventually developed in the late diagenetic period. However, this raises the question of whether the characteristic long-term shallow burial and the late, short-term, rapid deep burial at low temperature had an influence on $\Delta 47$ as an indicator of the formation temperature of the cements. Based on the burial and thermal histories of this area, it was found that the $\Delta 47$ of the calcareous cements in the Donghe sandstone is independent of the burial process, according to the reconstruction formula of $\Delta 47$ established by Henkes et al. [29], and can reflect the formation temperatures of the cements, as shown in Figure 8.

5.5. Implication for Reservoir Quality Prediction and Hydrocarbon Accumulation. The Donghe sandstone reservoirs in the Hadexun Oilfield are divided into the upper edge-water stratified reservoir and the lower bottom-water massive reservoir (Figure 9). Crude oil in the Donghe sandstone reservoirs is characterized by medium-high density (average of $\left.0.898 \mathrm{~g} / \mathrm{cm}^{3}\right)$, medium-high viscosity (10$20 \mathrm{MPa} \cdot \mathrm{s})$, low freezing temperature $\left(-4^{\circ} \mathrm{C}\right.$ to $\left.30^{\circ} \mathrm{C}\right)$, low sulfur content $(0.55-1.73 \%)$, low wax content (1.64$12.97 \%$ ), and high contents of gum and asphaltine (10.56$20.62 \%)$. The density of crude oil shows a gradual decreasing trend from northwest to southeast, ranging from $0.935 \mathrm{~g} / \mathrm{cm}^{3}$ 

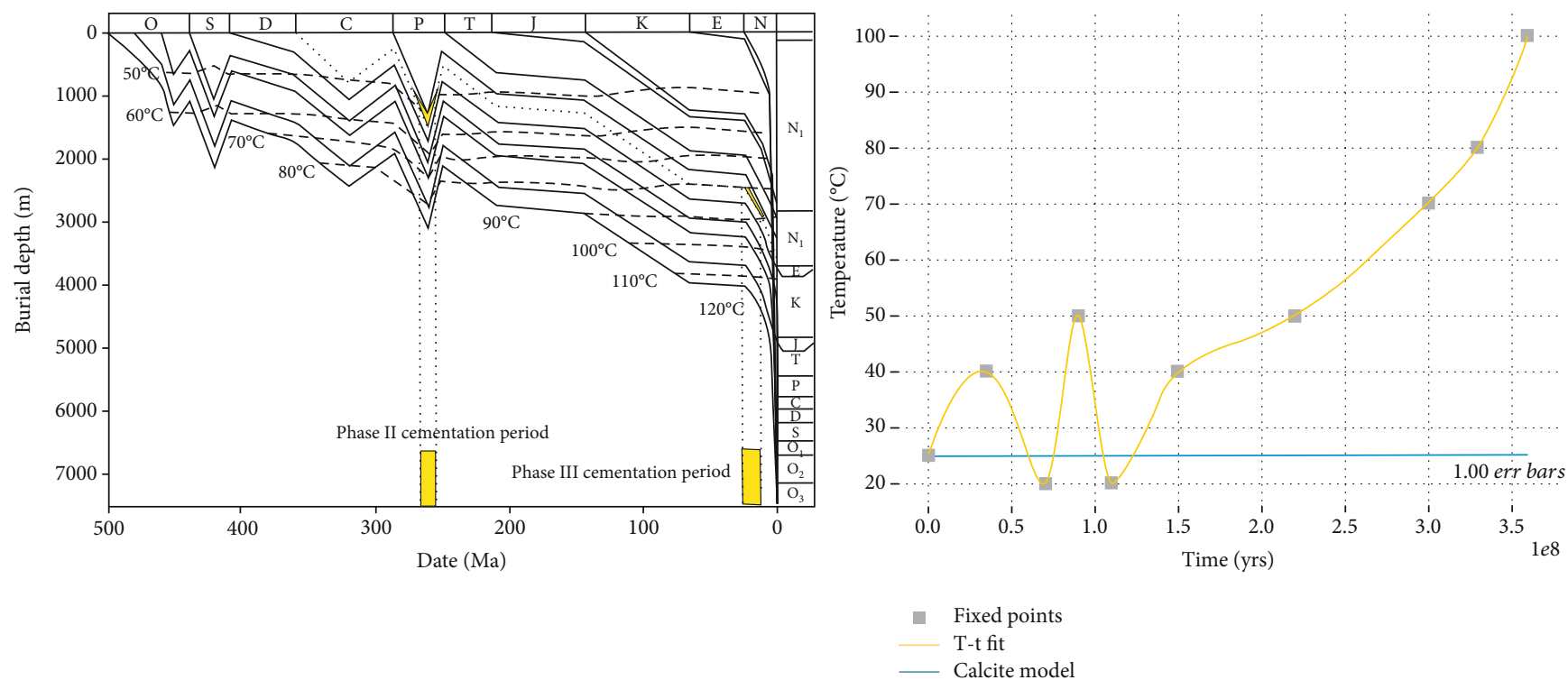

FIGURE 8: Influence of $\Delta 47$ on temperature calculation under the thermal burial history and burial history of the Tabei area (the burial history is modified from [51]).

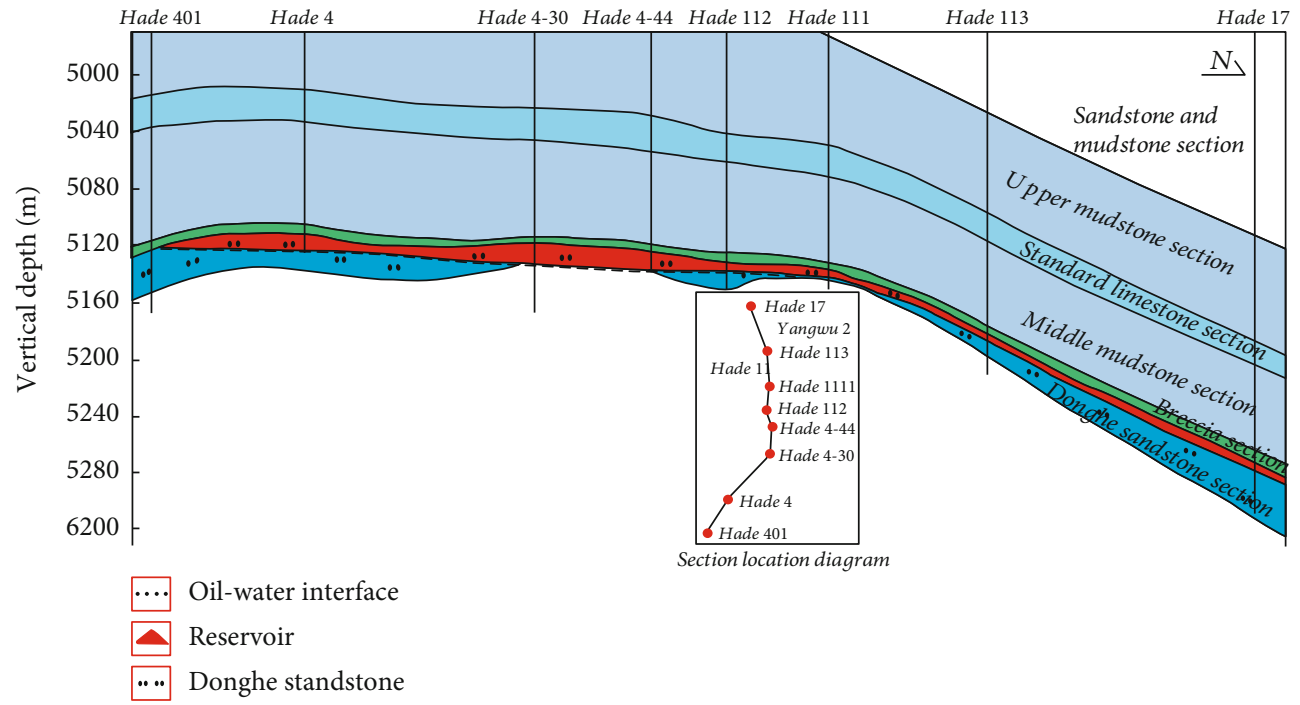

Figure 9: Reservoir profile of the Hadexun Oilfield.

to $0.870 \mathrm{~g} / \mathrm{cm}^{3}$, respectively. The Donghe sandstone reservoirs have relatively dense natural gas (1.02-1.23), belonging to typical wet gas, with low methane content of $15.46-34.32 \%$ and high nitrogen content of 30-40\%. The formation water, which is $\mathrm{CaCl}_{2}$ type, has an average density of $1.1584 \mathrm{~g} / \mathrm{cm}^{3}$, an average chloride content of $156,000 \mathrm{mg} / \mathrm{L}$, and an average total salinity of $257,000 \mathrm{mg} / \mathrm{L}$. Oil source correlation shows that the crude oils from the Lungu Oilfield and Tahe Oilfield in the Lunnan low bulge have the same oil source, CambrianOrdovician marine source rocks in the Mangar sag [6].

The homogenization temperatures of saline water inclusions associated with crude oil in the Hadexun area range from $100^{\circ} \mathrm{C}$ to $130^{\circ} \mathrm{C}$, and oil and gas were accumulated in a single stage. Based on the regional tectonic evolution and the burial and thermal evolution histories of the strata, the filling period of the crude oil of the Hadexun Oilfield was 8-5 Ma, within the Miocene period. The major filling period of crude oil in the reservoirs is obviously later than the formation time of the calcareous cements. It is inferred that the formation time of the calcite-cemented layers is the early diagenetic cementation stage and that the uncemented sandstone reservoirs are secondary reservoirs formed in the late diagenetic period, as shown in Figure 10. After conducting analyses of the water power and capillary force to identify the causes of the inclined oil-water interface in the Hadexun Oilfield, some scholars concluded that the reservoirs were in an adjustment period, being unsteady reservoirs [3].

As speculated from the tectonic and burial histories, the oil and gas in the Hadexun area migrated laterally from paleoreservoirs near Well Xiang 3 in the north after the 

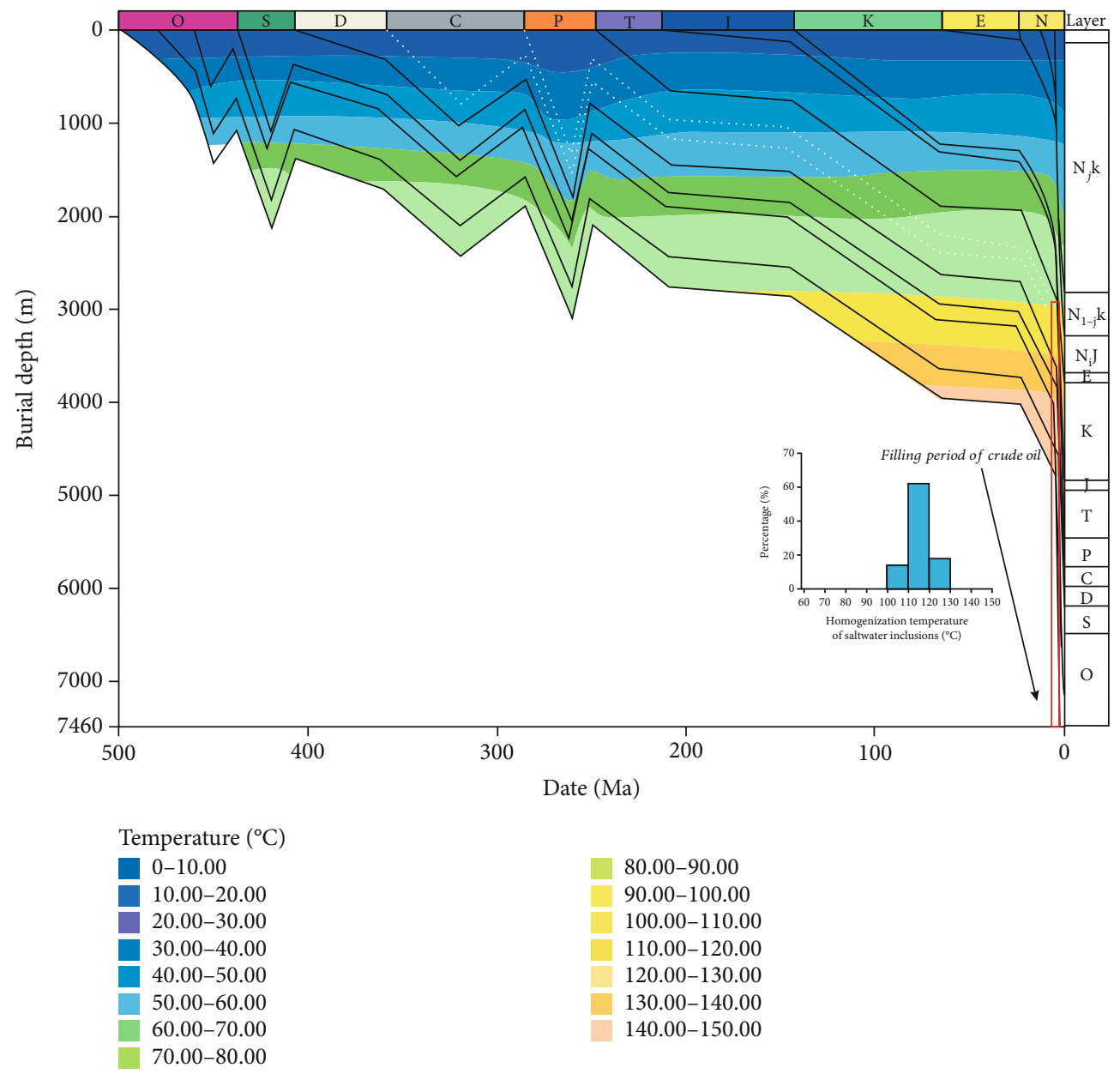

FIGURE 10: Formation time of calcareous interlayers and timing of oil charging in the Donghe sandstone in the Hadexun Oilfield, Tarim Basin (burial history is modified from $[6,51]$ ).

north-dipping slope was finalized in the late Himalayas, where a large number of dry asphalt intervals remain today. The Himalayan movement tilted the formations. As a result, some crude oil migrated to an unconformity before the Lunnan No. 1 fault. The unconformity is high in the south and low in the north and high in the middle and low in the east and west, forming a nose-shaped feature. Oil and gas migrated along the "bridge of the nose" to the Hadexun area, forming the Hadexun Oilfield [3]. It was also reported that the oil and gas may have migrated vertically along the fault [7]. Based on the fact that the calcareous cementation is much earlier than the oil accumulation and charge, this paper proposes that the formation of a large number of early calcite-cemented layers caused the oil, which had migrated and accumulated through carrier beds, to migrate along layers separated by them instead of along well-separated channels, forming the inconsistency of the present oil-water interface with the structural contours (the height difference was reported as $178.33 \mathrm{~m}$ by [2]).

\section{Conclusions}

Based on core observations, microheterogeneity, diagenetic features, diagenetic mineral compositions, and stable isotope analyses of the oiliness difference of calcareous interlayers in the Donghe sandstone, the following conclusions were drawn:

(1) It was concluded that calcareous cementation was the major factor resulting in porosity reduction of the tight sandstone. Thin section observations showed that calcareous cementation was also the major factor leading to the oil heterogeneity in the tight sandstone reservoir, and cathodoluminescence imaging revealed that multiphase calcareous cementation is mainly developed in the tight sandstone. Clumped isotope analysis indicated that the formation temperature of the carbonate cements ranges from $45^{\circ} \mathrm{C}$ to $90^{\circ} \mathrm{C}$, corresponding to the Early Cretaceous period. The cements are considered to be the products of the early diagenetic period and are related to early tectonic movement and late burial

(2) According to the homogenization temperatures of the coeval salt-water inclusions associated with hydrocarbon inclusions, ranging from $100^{\circ} \mathrm{C}$ to $130^{\circ} \mathrm{C}$, basin modeling revealed that the basin underwent mainly one stage of hydrocarbon charging 
during $8-5 \mathrm{Ma}$ in the Miocene period. Carbonate cements were developed before the massive accumulation of oil

(3) Cements in the oil-free calcareous interlayers in the Donghe sandstone are one of the main controlling factors of the oil-water distribution in the reservoirs at present. This study provides a basis for research into the role of carbonate-cemented sandstone in hydrocarbon accumulation and also provides referential techniques and operational procedures for the study of reservoir diagenesis and timing of accumulation

\section{Data Availability}

All data supporting the results of this study can be found included in this manuscript.

\section{Conflicts of Interest}

The authors declare that they have no conflicts of interest.

\section{References}

[1] Y. F. Liu, J. H. Zhao, Q. H. Fan, C. S. Lin, Q. Sun, and L. L. Huang, "Diagenesis and its control factors of Donghe Standstone in Hanilcatam Depression of Tabei Uplift," Geoscience, vol. 28, no. 3, pp. 635-644, 2014.

[2] X. Y. Zhou, H. J. Yang, Z. Z. Cai, F. Y. Zhao, and J. F. Hu, "Case of discovery and exploration of marine fields in China (part 10): Hadexun Sandstone Oilfield in Tarim Basin," Marine Origin Petroleum Geology, vol. 12, no. 4, pp. 51-60, 2007.

[3] D. L. Sun, T. W. Jiang, H. L. Xu, J. Z. Shan, and Z. G. Lian, "Unsteady reservoir in Hadson Oilfield, Tarim Basin," Petroleum Exploration and Development, vol. 36, no. 1, pp. 62-67, 2009.

[4] X. Y. Chen, P. Luo, J. H. Jia, D. B. Ma, and B. Zhou, "Provenances and sedimentary facies distribution in Carboniferous Donghe Sandstone in the central part of Northern Tarim Basin," Marine Origin Petroleum Geology, vol. 18, no. 2, pp. 23-30, 2013.

[5] J. Y. Gu, X. Y. Zhang, and B. C. Guo, "Characteristics of sedimentation and reservoir of the Donghe Sandstone in Tarim Basin and their synthetic analysis," Journal of Palaeogeography, vol. 8, no. 3, pp. 285-294, 2006.

[6] J. Su, S. C. Zhang, H. J. Yang, G. Y. Zhu, J. K. Mi, and Z. Y. Xiao, "Evidence of the organic geochemistry and petrology for the adjustment process of primary reservoir: insight into the adjustment mechanism of Hadexun oil field visa Xiang-3 Well," Acta Petrologica Sinica, vol. 27, no. 6, pp. 1886-1890, 2011.

[7] X. W. Tao, M. Li, J. H. Jia, D. B. Ma, and L. P. Zhang, "Geochemical characteristics of natural gases and type study of Donghe Standstone reservoir, Hadexun Oilfield in Tarim Basin," Natural Gas Geoscience, vol. 25, no. 1, pp. 70-78 $+123,2014$.

[8] Y. Wang, J. Liu, J. G. Wang et al., "Major controlling factors for the formation of inner-layer of Donghe Sandstone of Donghe 1 reservoir in Tarim Basin and its fluid source," Acta Petrolei Sinica, vol. 35, no. 2, pp. 174-181, 2015.
[9] Z. Y. Xiao, G. H. Huang, P. R. Wang, Q. C. Zhang, Y. H. Lu, and $\mathrm{X} . \mathrm{Y} . \mathrm{Hu}$, "Distribution of nitrogen compounds in oils and reservoir filling direction in Hadexun and its adjacent oilfields, Tarim Basin, NW China," Geochimica, vol. 32, no. 3, pp. 263-270, 2003.

[10] B. Zhou, J. H. Jia, and X. Y. Chen, "Petroleum migration patterns of Donghe Sandstone secondary hydrocarbon reservoir in North Tarim Basin and their implications for the future exploration," Journal of Southwest Petroleum University (Science \& Technology Edition), vol. 35, no. 4, pp. 25-34, 2013.

[11] X. M. Zhu, Q. Zhang, C. L. Zhao, and X. Y. Lv, "Sedimentary facies and environmental changes of the Donghe Sandstone in Central Tarim," Chinese Journal of Geology, vol. 39, no. 1, pp. 27-35, 2004.

[12] J. W. Zhao, H. M. Xu, T. W. Jiang et al., “The controlling effect of sea level changing on the microscopic heterogeneity of marine reservoir: taking shoreface subfacies reservoir of Donghe sandstone in Hade 4 oilfield as an example," Journal of China University of Mining \& Technology, vol. 47, no. 5, pp. 1068-1080, 2018.

[13] R. B. Han, Q. Liu, T. W. Jiang et al., "Feature, origin and distribution of calcareous interlayers: a case of Carboniferous Donghe sandstone in Hade Oil Field, Tarim Basin, NW China," Petroleum Exploration and Development, vol. 41, no. 4, pp. 428-437, 2014.

[14] Z. M. Wang, Q. H. Wang, L. X. Sun, Y. P. Li, and W. H. Li, "Main features of calcic-diagenesis in the Donghe Sandstones," Chinese Journal of Geology, vol. 39, no. 4, pp. 517-522, 2004.

[15] Y. Xu, H. M. Xu, C. T. Guo, Y. J. Niu, L. J. Chang, and T. Han, "Origin, characteristics and effects on oilfield development of interlayer of shore sandstone reservoir in Tazhong area," Science \& Technology Review, vol. 30, no. 15, pp. 17-21, 2012.

[16] H. Zhao, X. R. Luo, Z. Y. Xiao et al., "Interlayer features and petroleum geology meaning of Donghe Standstones in the Hadson Oilfield," Natrual Gas Geoscience, vol. 25, no. 6, pp. 824-833, 2014.

[17] J. H. Zhao, C. S. Lin, Y. F. Liu, J. Y. Liu, Q. H. Fan, and Q. Q. Fan, "Study on the high-resolution sequence stratigraphy and depositional systems of the Donghetang Formation in the central Tabei Uplift," Natural Gas Geosicence, vol. 25, no. 3, pp. 351-359, 2014.

[18] J. Lai, G. Wang, S. Wang et al., "Review of diagenetic facies in tight sandstones: diagenesis, diagenetic minerals, and prediction via well logs," Earth-Science Reviews, vol. 185, pp. 234258, 2018.

[19] S. Morad, K. Al-Ramadan, J. M. Ketzer, and L. F. De Ros, “The impact of diagenesis on the heterogeneity of sandstone reservoirs: a review of the role of depositional facies and sequence stratigraphy," AAPG Bulletin, vol. 94, no. 8, pp. 1267-1309, 2010.

[20] J. M. Eiler, "“Clumped-isotope" geochemistry-the study of naturally-occurring, multiply-substituted isotopologues," Earth and Planetary Science Letters, vol. 262, no. 3-4, pp. 309-327, 2007.

[21] J. M. Eiler, "Paleoclimate reconstruction using carbonate clumped isotope thermometry," Quaternary Science Reviews, vol. 30, no. 25-26, pp. 3575-3588, 2011.

[22] U. Brand, R. E. Came, H. Affek, K. Azmy, R. Mooi, and K. Layton, "Climate-forced change in Hudson Bay seawater composition and temperature, Arctic Canada," Chemical Geology, vol. 388, pp. 78-86, 2014. 
[23] J. Cui, S. Li, and Z. Mao, "Oil-bearing heterogeneity and threshold of tight sandstone reservoirs: a case study on Triassic Chang7 member, Ordos Basin," Marine and Petroleum Geology, vol. 104, pp. 180-189, 2019.

[24] K. W. Huntington and A. R. Lechler, "Carbonate clumped isotope thermometry in continental tectonics," Tectonophysics, vol. 647-648, pp. 1-20, 2015.

[25] Y. Shuai, G. Etiope, S. Zhang, P. M. J. Douglas, L. Huang, and J. M. Eiler, "Methane clumped isotopes in the Songliao Basin (China): new insights into abiotic vs. biotic hydrocarbon formation," Earth and Planetary Science Letters, vol. 482, pp. 213-221, 2018.

[26] Z. Y. Xiong, L. Ding, and J. Xie, "Carbonate clumped isotope $(\Delta 47)$ thermometry and its application in paleoelevation reconstruction," Chinese Science Bulletin, vol. 2019, no. 64, pp. 1722-1737, 2019.

[27] Q. C. Xu, N. S. Qiu, W. Liu, and Q. Chang, "Reconstructing the basin thermal history with clumped isotope (in Chinese)," Chinese Science Bulletin, vol. 2019, no. 64, pp. 566-578, 2019.

[28] E. A. Schauble, P. Ghosh, and J. M. Eiler, "Preferential formation of ${ }^{13} \mathrm{C}-{ }^{18} \mathrm{O}$ bonds in carbonate minerals, estimated using first-principles lattice dynamics," Geochimica et Cosmochimica Acta, vol. 70, no. 10, pp. 2510-2529, 2006.

[29] G. A. Henkes, B. H. Passey, A. D. Wanamaker Jr., E. L. Grossman, W. G. Ambrose Jr., and M. L. Carroll, "Carbonate clumped isotope compositions of modern marine mollusk and brachiopod shells," Geochimica et Cosmochimica Acta, vol. 106, pp. 307-325, 2013.

[30] D. A. Stolper and J. M. Eiler, "The kinetics of solid-state isotope-exchange reactions for clumped isotopes: a study of inorganic calcites and apatites from natural and experimental samples," American Journal of Science, vol. 315, no. 5, pp. 363-411, 2015.

[31] K. J. Dennis, H. P. Affek, B. H. Passey, D. P. Schrag, and J. M. Eiler, "Defining an absolute reference frame for 'clumped' isotope studies of $\mathrm{CO}_{2}$," Geochimica et Cosmochimica Acta, vol. 75, no. 22, pp. 7117-7131, 2011.

[32] R. Development Core Team, R: A Language and Environment for Statistical Computing, R Foundation for Statistical Computing, Vienna, Austria, 2011.

[33] M. Bonifacie, D. Calmels, J. M. Eiler et al., "Calibration of the dolomite clumped isotope thermometer from 25 to $350^{\circ} \mathrm{C}$, and implications for a universal calibration for all $(\mathrm{Ca}, \mathrm{Mg}$, $\mathrm{Fe} \mathrm{CO}_{3}$ carbonates," Geochimica et Cosmochimica Acta, vol. 200, pp. 255-279, 2017.

[34] H. L. Guo and D. R. Wang, "Stable isotopic composition and origin analysis the carbonate cements within sandstone reservoirs of Tarim oil-gas bearing area," Petroleum Exploration and Development, vol. 26, no. 3, pp. 31-32, 1999.

[35] R. K. Zhu, P. Luo, and Z. Luo, “The isotope geochemistry characteristics of carbonate rocks in Carboniferous in Tarim Basin," Xinjiang Petroleum Geology, vol. 23, no. 5, pp. 282284, 2002

[36] R. C. Zheng, H. D. Chen, S. N. Zhang, and D. M. Li, "Stable isotopic characteristics of karst-reservoirs in Huanglong Formation from Eastern Sichuan," Earth Science-Journal of China University of Geosciences, vol. 22, no. 4, pp. 424-428, 1997.

[37] M. L. Keith, G. M. Anderson, and R. Eichler, "Carbon and oxygen isotopic composition of mollusk shells from marine and fresh-water environments," Geochimica et Cosmochimica Acta, vol. 28, no. 10-11, pp. 1757-1786, 1964
[38] Z. M. Wang, H. W. Xie, Y. Li et al., "Exploration and discovery of large and deep subsalt gas fields in Kuqa Foreland Thrust Belt," China Petroleum Exploration, vol. 18, no. 3, pp. 1-11, 2013.

[39] P. A. Bjørkum and O. Walderhaug, "Geometrical arrangement of calcite cementation within shallow marine sandstones," Earth-Science Reviews, vol. 29, no. 1-4, pp. 145-161, 1990.

[40] I. Friedman and J. R. O' Neil, Compilation of Stable Isotope Fractionation Factors of Geochemical Interest, Data of Geochemistry. U.S.Geology Survey, Houston, 1977.

[41] J. R. O'Neil, R. N. Clayton, and T. K. Mayeda, "Oxygen isotope fractionation in divalent metal carbonates," The Journal of Chemical Physics, vol. 51, no. 12, pp. 5547-5558, 1969.

[42] J. Tang, M. Dietzel, A. Fernandez, A. K. Tripati, and B. E. Rosenheim, "Evaluation of kinetic effects on clumped isotope fractionation $(\Delta 47)$ during inorganic calcite precipitation," Geochimica et Cosmochimica Acta, vol. 134, pp. 120-136, 2014.

[43] S. M. Bernasconi, I. A. Müller, K. D. Bergmann et al., "Reducing uncertainties in carbonate clumped isotope analysis through consistent carbonate-based standardization," Geochemistry, Geophysics, Geosystems, vol. 19, no. 9, pp. 28952914, 2018.

[44] K. J. Dennis and D. P. Schrag, "Clumped isotope thermometry of carbonatites as an indicator of diagenetic alteration," Geochimica et Cosmochimica Acta, vol. 74, no. 14, pp. 41104122, 2010.

[45] R. A. Eagle, J. M. Eiler, A. K. Tripati et al., "The influence of temperature and seawater carbonate saturation state on ${ }^{13} \mathrm{C}-{ }^{18} \mathrm{O}$ bond ordering in bivalve mollusks," Biogeosciences, vol. 10, no. 7, pp. 4591-4606, 2013.

[46] P. Ghosh, J. Adkins, H. Affek et al., ${ }^{~}{ }^{13} \mathrm{C}-{ }^{18} \mathrm{O}$ bonds in carbonate minerals: a new kind of paleothermometer," Geochimica et Cosmochimica Acta, vol. 70, no. 6, pp. 1439-1456, 2006.

[47] G. A. Henkes, B. H. Passey, E. L. Grossman, B. J. Shenton, A. Pérez-Huerta, and T. E. Yancey, "Temperature limits for preservation of primary calcite clumped isotope paleotemperatures," Geochimica et Cosmochimica Acta, vol. 139, pp. 362-382, 2014.

[48] P. S. Hill, A. K. Tripati, and E. A. Schauble, "Theoretical constraints on the effects of ph, salinity, and temperature on clumped isotope signatures of dissolved inorganic carbon species and precipitating carbonate minerals," Geochimica et Cosmochimica Acta, vol. 125, pp. 610-652, 2014.

[49] R. C. Surdam, L. J. Crossey, S. E. Hagen, and H. P. Heasler, "Organic-inorganic interactions and sandstone diagenesis," AAPG Bulletin, vol. 73, no. 1, pp. 1-23, 1989.

[50] S. H. Wu and Q. H. Xiong, Hydrocarbon Reservoir Geology, Petroleum Industry Press, Beijing, 1997.

[51] S. C. Meng, Invisitigation on Marine Oil and Gas Accumulation in the Carboniferous Reservoirs in the Northern Tarim Basin: [Dissertation], China University of Petroleum, Qingdao, 2010. 